\title{
Case Report: Cardiac Involvement in Trichinellosis: A Case of Left Ventricular Thrombosis
}

\author{
Diana Tint,* Maria E. Cocuz, Ovidiu F. Ortan, Mihai D. Niculescu, and Mariana Radoi \\ School of Medicine, Transilvania University in Brasov, Brasov, Romania; ICCO Clinics, Brasov, \\ Romania; Nutrition Research Institute at Kannapolis, Department of Nutrition, \\ University of North Carolina at Chapel Hill, Chapel Hill, North Carolina
}

\begin{abstract}
We report the case of a 42-year-old woman who was admitted to the hospital for fever, chills, nausea, vomiting, fatigue, myalgia, and general muscle weakness. All these symptoms had occurred 3 weeks after the ingestion of inadequately cooked pork meat, subsequently confirmed to be infested with Trichinella spiralis. Laboratory results showed mild leukocytosis, inflammation, and mild liver and muscle cytolytic syndrome, all suggestive of trichinellosis. Echocardiography showed apical hypokinesis and an apical mass (likely a thrombus). The immunologic assessment for the presence of Trichinella antigens was positive. The outcome was favorable after treatment with an anticoagulant, an antiaggregant, prednisone, and mebendazole. Follow-up controls showed the absence of any symptoms and thrombus, with only mild electrocardiogram modifications still present.
\end{abstract}

\section{INTRODUCTION}

The etiology of most human cases of trichinellosis (trichinosis) consists of species of the intestinal nematode Trichinella spiralis. Although the most frequent symptoms described were gastrointestinal disorders, myalgia, fever, palpebral and facial edema, and marked eosinophilia, ${ }^{1}$ other isolated symptoms were also reported. Cardiovascular involvement included ventricular endocarditis and thrombosis at various sites (intraventricular, arterial, venous, sagittal sinus) and various types of electrocardiographic (ECG) abnormalities. ${ }^{2-7}$

We report a case of non-fatal left ventricular thrombosis associated with trichinellosis that, to our knowledge, is the third such case ever reported.

\section{CASE REPORT}

We report the case of a 42-year-old woman who was admitted to the Brasov Hospital of Infectious Diseases (Romania) for fever, chills, nausea, vomiting, fatigue, myalgia, and general muscle weakness. All these symptoms had occurred 10 days before hospitalization, at 3 weeks after the ingestion of inadequately cooked pork meat. The pork meat was confirmed to be infested with T. spiralis. The patient was a current smoker (10 cigarettes/day), alcohol abstinent, and pre-menopausal, with no relevant history of medical or surgical conditions, including cardiovascular involvement.

After a routine ECG performed at the Infectious Disease Department, the patient was transferred to the Cardiology Department because of abnormal ECG recordings. Physical examination was unremarkable. We found regular tachycardia (110 beats/min), absence of the third sound, no cardiac and/or vascular murmurs, blood pressure $100 / 60 \mathrm{~mm}$ of $\mathrm{Hg}$, no facial edema, no signs of heart failure, and no neurologic signs.

A complete blood count showed mild leukocytosis $(8.68 \times$ $10^{3}$ cells $/ \mu \mathrm{L}$, normal $=4.0-8.0 \times 10^{3}$ cells $\left./ \mu \mathrm{L}\right)$ with left shift and $32.9 \%$ eosinophils (absolute eosinophilia, $2.8 \times 10^{3} / \mu \mathrm{L}$ ). Blood biochemistry indicated an inflammatory syndrome characterized by a highly positive $(++++)$ test for $\mathrm{C}$ reactive protein, elevated plasma fibrinogen $(450 \mathrm{mg} / \mathrm{dL})$, and red blood cell

*Address correspondence to Diana Tint, Transilvania University of Brasov, School of Medicine, 56 Nicolae Balcescu Street, 500019 Brasov, Romania. E-mail: dianatint@yahoo.com
(RBC) sedimentation rate of $56 \mathrm{~mm}$ at 1 hour. Other abnormal biochemical findings indicated a mild liver cytolytic syndrome: alanine transaminase (ALT), $54 \mathrm{UI} / \mathrm{L}$; aspartate transaminase (AST), $29 \mathrm{UI} / \mathrm{L}$; elevated troponin I, phosphocreatine kinase (MB fraction and total), and lactate dehydrogenase (LDH; $1.06 \mathrm{ng} / \mathrm{dL}, 3.23 \mathrm{ng} / \mathrm{dL}, 284 \mathrm{UI} / \mathrm{L}$, and $309 \mathrm{UI} / \mathrm{L}$, respectively).

The clinical presentation, together with the laboratory tests, were highly indicative for human trichinellosis. ${ }^{1}$

An ECG was performed again at admission into the Cardiology Department, indicating widespread ST segment depression (I, II, aVF, V3-V6) and inverted T waves in III and V3-V6 (Figure 1).

A cardiac echocardiography examination (Sonos Agilent 4500, Philips Healthcare, Best, The Netherlands) showed normal-sized cavities and a significant area of apical hypokinesis with an apical mass, highly suggestive for thrombus. No pericardial effusion was noticed (Figure 2).

Combined anticoagulant (enoxaparin, $1 \mathrm{mg} / \mathrm{kg}$ body weight, three times a day) and antiaggregant administration (aspirin, $75 \mathrm{mg}$, four times a day) was immediately started, whereas therapy with prednisone $(60 \mathrm{mg} / \mathrm{d})$ and mebendazole $(100 \mathrm{mg}$, 4 times a day) had already started 6 days earlier. The outcome was favorable, characterized by the reduction of eosinophil percentage, remission of the inflammatory syndrome, and reduction in size of the ventricular mass under heparin administration. The patient left the hospital after 21 days, with the indication of continuing the oral anticoagulant therapy with acenocoumarol until achieving a targeted international normalized ratio (INR) value of 2.5 in the next months (under routine outpatient medical supervision).

Two months later, the patient returned to the hospital for a scheduled elective invasive angiographic examination and follow-up ECG and blood biochemistry. The angiographic evaluation showed normal coronary arteries with normal left ventricular ejection fraction (LVEF; Figure 3). The ECG recording still showed inverted T waves in V4-V6. Repeated echocardiography showed normal size of cavities, normal wall motion, no intra-cardiac mass, and normal LVEF. Laboratory findings were as follows: white blood cell count, $6.0 \times 10^{3} / \mu \mathrm{L}$ with $0.8 \%$ eosinophils; ALT, $5.4 \mathrm{UI} / \mathrm{L}$; AST, $8.3 \mathrm{UI} / \mathrm{L}$; normal total CK, $49.8 \mathrm{UI} / \mathrm{L}$. An enzyme-linked immunosorbent assay (ELISA) test for IgG antibodies to conserved immunodominant Trichinella antigens was performed in May 2008, and a positive result was obtained (RIDA SCREEN, DSX4 


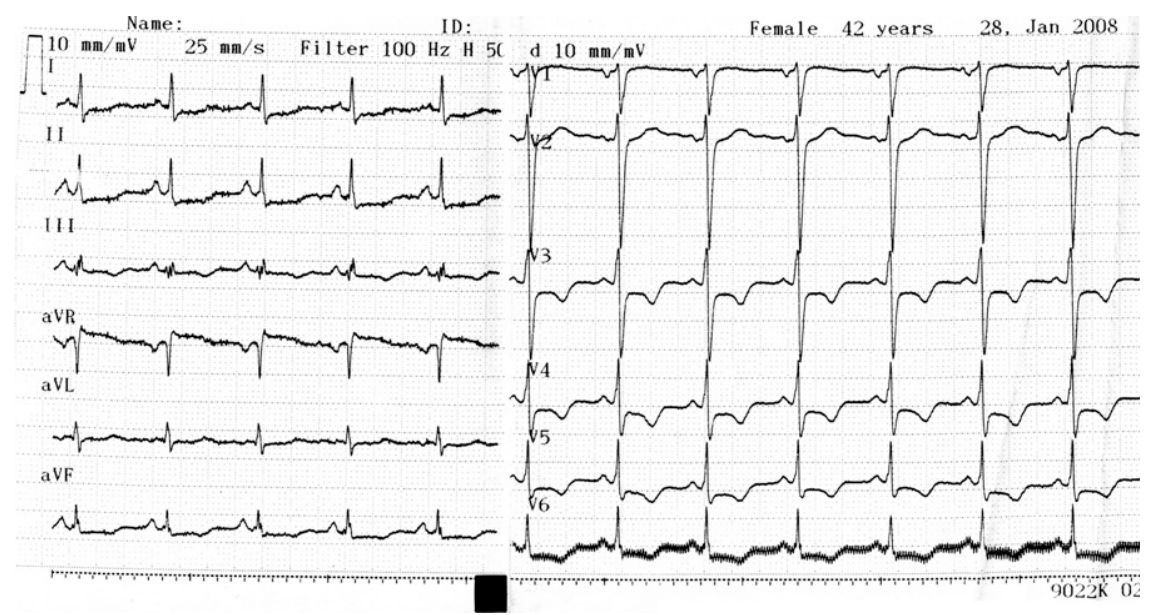

FIGURE 1. ECG at admission to the cardiology department.

R-Biopharm Aktiengesellschaft, Darmstadt, Germany; 1.7 optical density [OD] units; positive $>0.3$ OD units) using rabbit and human sera as positive and negative controls, respectively. Thus, the diagnosis of trichinellosis was confirmed (the test has $100 \%$ specificity after 50 days from onset ${ }^{8}$ ).

A second follow-up examination was performed in August 2008 (8 months after onset). The patient was free of symptoms. The ECG still showed ST segment depression in II, III, aVF, and V3-V6 (Figure 4). Repeated echocardiography showed normal cavities with no mass inside, preserved left ventricular systolic function, and normal wall movements (Figure 5).

\section{DISCUSSION}

Trichinellosis is a common disease, with cardiac involvement occurring in between $10 \%$ and $60 \%$ of all patients; most of the myocardial changes occur during the invasive phase with T. spiralis. ${ }^{9,10}$ The most common sign of cardiac involvement in non-fatal trichinellosis consists of ECG changes. According to published data, these changes are ventricular repolarization disturbances, bundle-branch conduction disturbances, and sinus tachycardia, all of which become obvious in the invasive phase and some persist sometimes for a few months after hospital discharge, thus representing evidence of prolongation of the inflammatory process within the myocardium. ${ }^{7}$ Other ECG modifications during various phases of the infection consist of sinus bradycardia, right bundle-branch block, supraventricular and ventricular premature beats, low-voltage QRS complexes in standard limb leads, first-degree atrio-ventricular block, and atrial fibrillation. ${ }^{7,10}$ Although such ECG abnormalities seem to be a common feature of trichinellosis, especially during the invasive phase of the disease, they are rarely associated with a poor prognosis. ${ }^{9,10}$

One particular feature of this case is the lack of resolution for ECG alterations after 8 months from hospital discharge, despite the normal aspect of coronary arteries and the absence of myocarditis signs. Usually such changes are persistent for 3-4 weeks, whereas longer persistence may be associated with myocarditis. ${ }^{11,12}$

In our reported case, the elevation of $\mathrm{CK}, \mathrm{CK}-\mathrm{MB}$, and troponin, altogether with segmental hypokinesia, suggested myocardial involvement despite the normal cardiac dimensions and normal global LVEF. Neurologic and/or cardiac involvement is usually associated with very marked hyper-eosinophilia
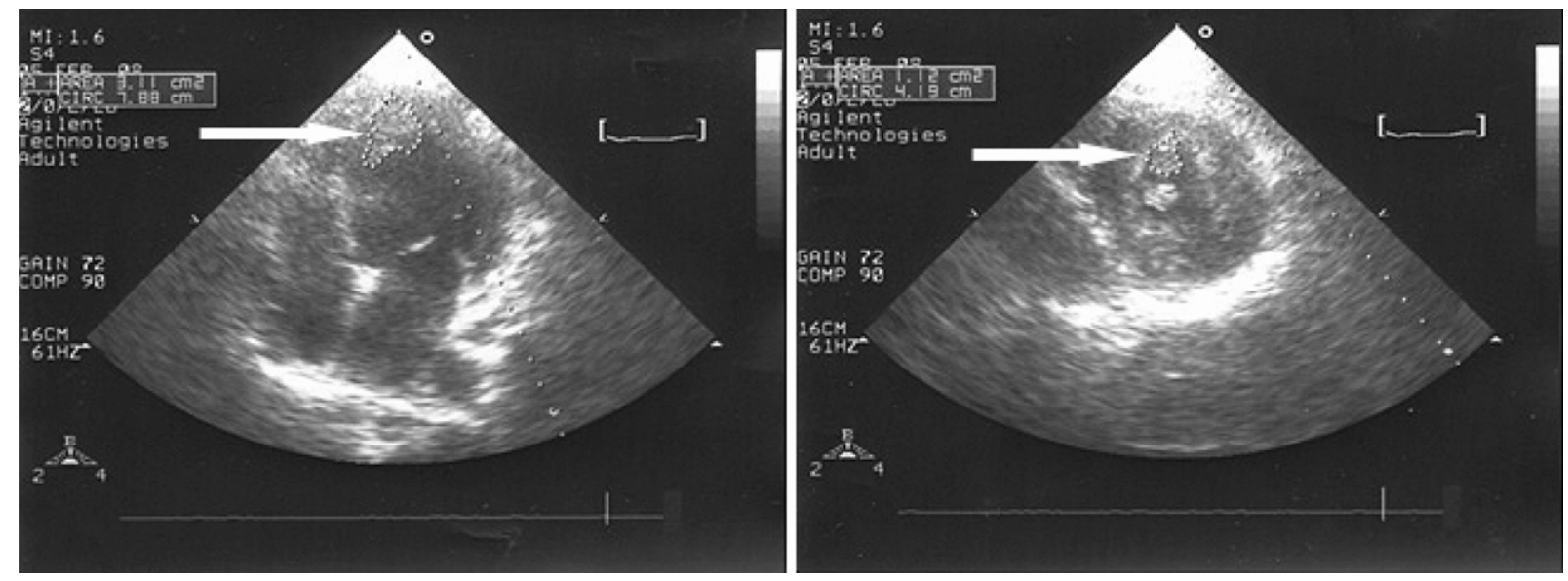

Figure 2. Two-dimensional cardiac echocardiogram. Left, Four chambers view. Right, Parasternal transversal view of a section at the level of papillary muscles. Thrombus presence is indicated by white arrows. 

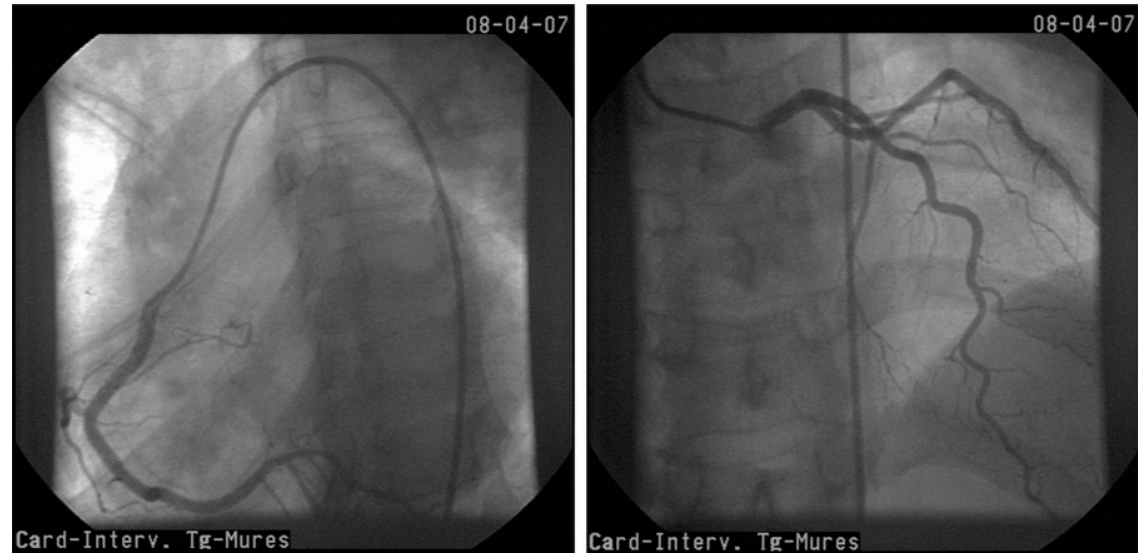

FIGURE 3. Angiographic assessment. Right, Normal aspect of the right coronary artery. Left, Normal aspect of the left main coronary artery, with the left anterior descending artery and circumflex artery.

( $\geq 4,000$ granulocytes $/ \mu \mathrm{L}) .{ }^{9,10}$ However, a lower count of eosinophils (as in the present case) could not rule out myocarditis. Although the patient did not have clinical or ultrasound features suggestive of myocarditis, it is possible that the apical hypokinesis was triggered by localized myocarditis, as recently described. ${ }^{13}$ However, cardiac magnetic resonance imaging assessment was not available, and myocardial biopsy was not performed. Based on angiographic imaging of the coronary arteries, one can exclude atherosclerotic coronary artery disease. It is relatively unlikely that the transient apical hypokinesis was caused by coronary thrombosis: complete coronary thrombosis usually does not lead to transient hypokinesis but more often to infarction and scar.

Another very intriguing possibility is that the trichinellosis did not cause the apical dysfunction directly, but that-by causing a severe systemic disease with significant stress-the
Trichinella infection led to Tako-Tsubo cardiomyopathy (transient apical ballooning syndrome). This phenomenon has been increasingly recognized around the world and is much more common in women than in men. ${ }^{14}$

The favorable outcome for our subject after anticoagulant therapy supports the hypothesis of ventricular thrombus with subsequent dissolution.

Cardiac involvement in Trichinella infection has already been reported in the literature, with different degrees of severity, including fatal acute myocardial infarction. ${ }^{7}$ However, only two cases were previously reported to involve ventricular thrombosis. Andy and others ${ }^{4}$ reported a case of fatal trichinellosis associated with extensive ventricular endocardial damage and superimposed thrombosis. In an echocardiographic study of the cardiac changes in trichinellosis, Vujisic et $a{ }^{15}$ reported a second case of intra-cavitary thrombus in one patient. Here

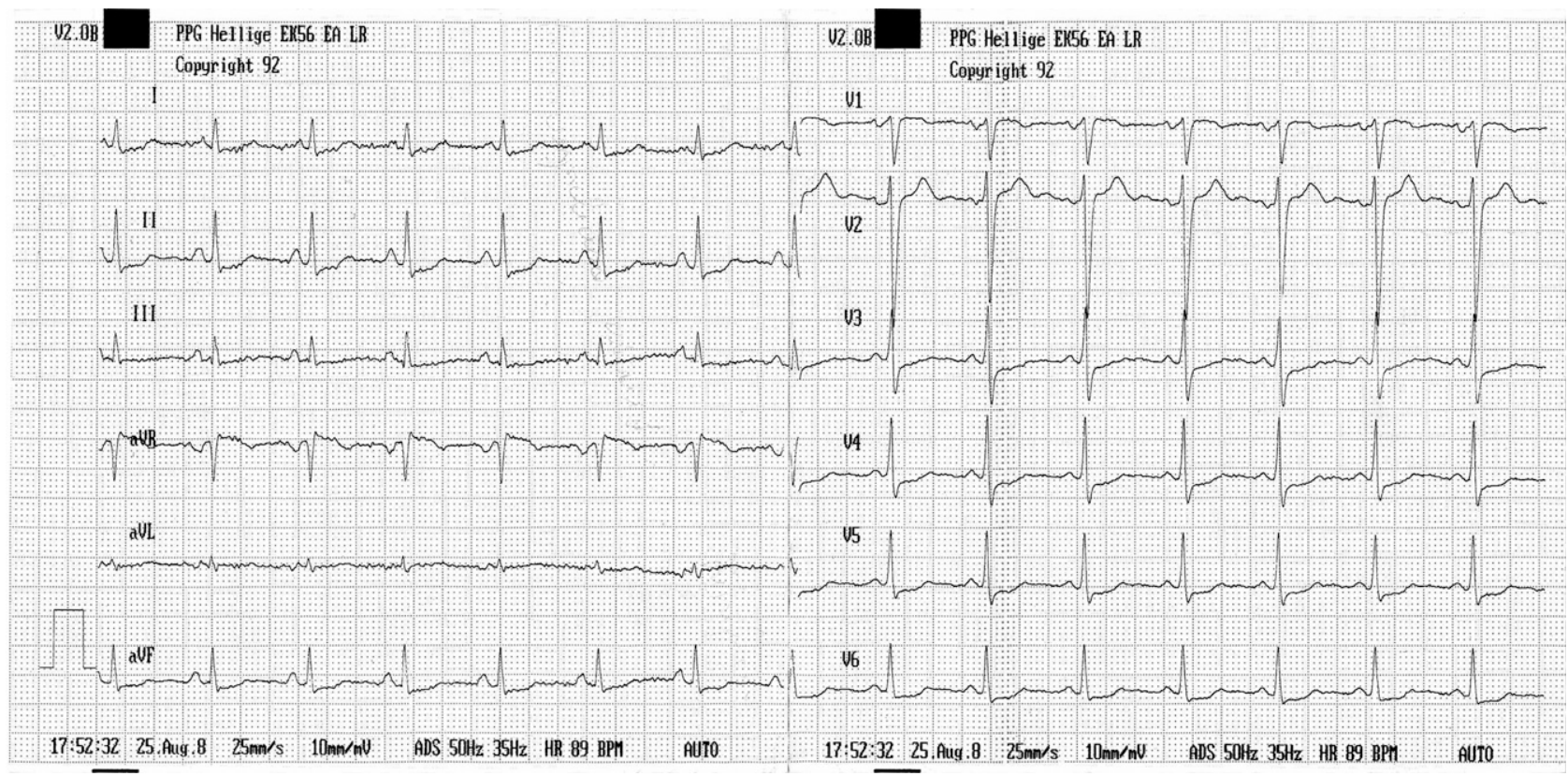

FIGURE 4. Second follow-up ECG. 

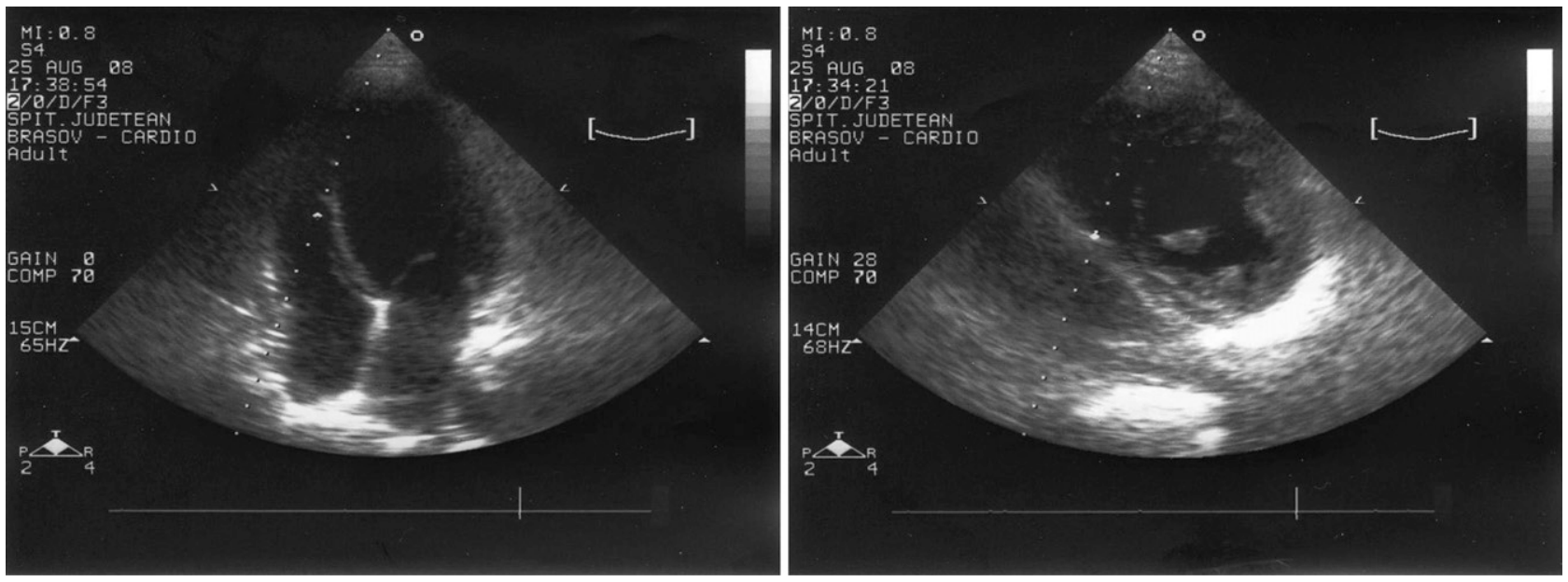

FIGURE 5. Follow-up echocardiography (after 8 months) showed absence of thrombus. Left, Four chambers view. Right, Parasternal transversal view of a section at a level including papillary muscles.

we report a third case of ventricular thrombosis that, under correct treatment, had a favorable outcome.

Received March 17, 2009. Accepted for publication April 22, 2009.

Authors' addresses: Diana Tint, Maria E. Cocuz, and Mariana Radoi, Transilvania University of Brasov, School of Medicine, 56 Nicolae Balcescu Str., 500019 Brasov, Romania. Mihai D. Niculescu, UNC Nutrition Research Institute, 500 Laureate Way, Kannapolis, NC28081. Ovidiu F. Ortan, ICCO Clinics, 8 Scolii Str., 500059 Brasov, Romania (current address), and Cardiology and Transplant Clinic, Cardiology Center, Targu Mures, Romania (former address).

Reprint requests: Diana Tint, Transilvania University of Brasov, School of Medicine, 56 Nicolae Balcescu Str., 500019 Brasov, Romania, Tel/Fax: 40-268-412185, E-mail: dianatint@yahoo.com.

\section{REFERENCES}

1. Gottstein B, Pozio E, Nockler K, 2009. Epidemiology, diagnosis, treatment, and control of trichinellosis. Clin Microbiol Rev 22: $127-145$.

2. el Koussa S, Chemaly R, Fabre-Bou Abboud V, Tamraz J, Haddad $\mathrm{N}, 1994$. [Trichinosis and cerebral sinocavernous thrombosis]. Rev Neurol (Paris) 150: 464-466.

3. Evans RW, Pattern BM, 1982. Trichinosis associated with superior sagittal sinus thrombosis. Ann Neurol 11: 216-217.

4. Andy JJ, O'Connell JP, Daddario RC, Roberts WC, 1977. Trichinosis causing extensive ventricular mural endocarditis with superimposed thrombosis. Evidence that severe eosinophilia damages endocardium. Am J Med 63: 824-829.

5. Klimowicz J, Lotocka K, Warejko S, 1964. [Venous thrombosis with dysfunction of the lymphatic system in the clinical picture of trichinosis based on 2 observations.]. Wiad Parazytol 10: 334-335.

6. Covey JA, Mc MJ, Myers HL, 1949. Trichinosis as a cause of major arterial thrombosis. J Am Med Assoc 140: 1212.

7. Puljiz I, Beus A, Kuzman I, Seiwerth S, 2005. Electrocardiographic changes and myocarditis in trichinellosis: a retrospective study of 154 patients. Ann Trop Med Parasitol 99: 403-411.

8. Morakote N, Sukhavat K, Khamboonruang C, Siriprasert V, Suphawitayanukul S, Thamasonthi W, 1992. Persistence of IgG, $\mathrm{IgM}$, and $\mathrm{IgE}$ antibodies in human trichinosis. Trop Med Parasitol 43: 167-169.

9. Bessoudo R, Marrie TJ, Smith ER, 1981. Cardiac involvement in trichinosis. Chest 79: 698-699.

10. Fourestie V, Douceron H, Brugieres P, Ancelle T, Lejonc JL, Gherardi RK, 1993. Neurotrichinosis. A cerebrovascular disease associated with myocardial injury and hypereosinophilia. Brain 116: 603-616.

11. Dupouy-Camet J, Kociecka W, Bruschi F, Bolas-Fernandez F, Pozio E, 2002. Opinion on the diagnosis and treatment of human trichinellosis. Expert Opin Pharmacother 3: 1117-1130.

12. Siwak E, Dron D, Pancewicz S, Zajkowska J, Snarska I, Szpakowicz T, Januszkiewicz E, 1994. [Changes in ECG examination of patients with trichinosis]. Wiad Lek 47: 499-502.

13. Kerebel S, Paule P, Jego C, La Folie T, Cellarier G, Poyet R, Laurent $\mathrm{P}$, Bouchiat C, Carlioz R, 2008. [Myocarditis caused by Trichinella spiralis: a case report]. Ann Cardiol Angeiol (Paris) 57: $127-130$.

14. Vizzardi E, D'Aloia A, Zanini G, Fiorina C, Chiari E, Nodari S, Dei Cas L, 2008. Tako-tsubo-like left ventricular dysfunction: transient left ventricular apical ballooning syndrome. Int J Clin Pract. Epub ahead of print.

15. Vujisic B, Najdanovic L, Simic N, 1991. [Cardiac trichinosisechocardiographic study]. Glas Srp Akad Nauka [Med] 40: 113-116. 